\title{
Cloning and expression analysis of GATA1 gene in Carassius auratus red var
}

\author{
Yusu Tian' ${ }^{1}$, Yuandong Sun ${ }^{1 *}$ (D, Mi Ou' ${ }^{2}$ Xiaojuan Cui ${ }^{1}$, Dinggang Zhou ${ }^{1}$ and Wen'an Che ${ }^{1}$
}

\begin{abstract}
Background: GATA1 is a key transcription factor in the GATA family, and promotes the differentiation and maturation of red blood cell, which is essential for normal hematopoiesis.

Results: Our results showed that the cDNA sequence of GATA1 was 2730 bp long encoding 443 amino acids. qRTPCR analysis demonstrated that GATA1 had the highest expression in testis (T), followed by pituitary $(P)$ and spleen (S). GATA1 gene expression in C. auratus red var. embryo from the neuroblast stage $(\mathrm{N})$ to the embryo hatching $(\mathrm{H})$ changes continuously; and the gene expression levels of nonylphenol (NP)-treated and those of control embryos were significantly different. Moreover, Methylation levels of GATA1 gene in NP-treated embryos were higher than those in control embryos, indicating that NP affected GATA1 methylation.
\end{abstract}

Conclusions: Our study provides cues for further studying the roles of GATA1 gene in fish development, and suggested a potential molecular mechanism by which NP leads to abnormal development of fish embryos.

Keywords: Carassius auratus red var.., GATA1, Cloning, Methylation, Expression characteristics

\section{Background}

Nonylphenol (NP), an environmental hormone that mimics estrogen and binds to its receptors in the cell, interferes with endocrine metabolism and has toxic effects on animals [1]. Studies demonstrated that NP was detrimental to reproduction. For example, NP causes male reproductive dysfunction, damages the development of testis, and leads to the decline of male fertility and sperm counts [2]. A low 4-NP (a typical isomer of para-NP) dosage induced uterine nutrition response in prepuberty rats, but not in ovariectomized adult rats [3]. Tanaka et al. showed that Rivulus marmoratus had abnormal gonadal development and testis insufficiency when exposed to NP [4]. In Oryzias latipes, the percentage of motile spermatozoa after sperm exposure to NP decreased dramatically [5]. However, although 4-NP did

\footnotetext{
* Correspondence: syd@hnust.edu.cn

${ }^{1}$ Hunan Key Laboratory of Economic Crops Genetic Improvement and Integrated Utilization, School of Life Sciences, Hunan University of Science and Technology, Xiangtan 411201, Hunan, People's Republic of China Full list of author information is available at the end of the article
}

affect sperm production in Oncorhynchus mykiss, it showed no effect on sperm density, motility and fertility [6]. NP not only affected adult fish, but also interfered with fish embryonic development. When Puntius conchonius embryos were exposed to NP, they showed developmental abnormalties such as egg coagulation, spinal deformity, and delayed development [7]. NP had drastic toxicity to development of goldfish embryos, which showed higher sensitivity to low concentrations of NP than adult fish [8]. 4-NP also affected the development of embryos and larvae of Oncorhynchus mykiss at the end of the yolk sac stage, reducing their survival rate [6]. In NP-exposured zebrafish embryos, the distribution of PGCs along the anterior-posterior axis in 24-h-old embryos changed, which may influence the juvenile and adult gonadal structures [9].

There have been some studies on the effects of NP on gene expression in vivo. Xia et al. reported that the expression of cy5 and cy3 in the rat was down-regulated under NP exposure [10]. When Chironomus riparius larvae were treated with $\mathrm{NP}$, the expression level of $\mathrm{CrEcR}$ 
was significantly up-regulated, through which nonylphenol might have significant implications in various developmental stages of C. riparius [11]. P353-NP (a typical isomer of para-NP) caused embryonic dysplasia in zebrafish (Danio rerio), with the expression of $n t l$ and spt unchanged but that of $t b x 6$ significantly increased [12]. Nonylphenol exposure reduced $\mathrm{Na}^{+} / \mathrm{K}^{+}$-ATPase activity, plasma cortisol and triiodothyronine levels in Salmo salar gills [13]. In addition, another study in Salmo salar suggests NP could regulate the hepatic enzyme activities that were mediated by Сур3a and Cyp1a1 through Pxr and Ahr. Furthermore, NP might have impacts on metabolism of both endogenous and exogenous substrates [14]. Paolo et al. found that significantly higher PPAR $\alpha$ mRNA levels in Solea solea were associated with 4-NP treatment for 3 days while the highest dose of 4-NP in their study also led to up-regulation of retinoid $\mathrm{X}$ receptor $\alpha(\mathrm{RXR} \alpha)$ transcription [15].

GATA1 is a key transcription factor for erythropoiesis, and it contains three conserved functional domains: Czinc finger, $\mathrm{N}$-zinc finger, and $\mathrm{N}$-terminal activation [16]. The two zinc finger domains are responsible for DNA binding and protein-protein interactions, which allow them to recognize typical GATA binding sites with a consensus sequence WGATAR [17]. GATA1 is indispensable in differentiation of erythroid cells and megakaryocytes. In the development of erythroid cells, GATA1 functions early in megakaryocytes. GATA1 controls terminal maturation and its deficiency induces proliferation [18]. Galloway established a transcriptional hierarchy dependent on GATA in the process of hematopoiesis, and demonstrated that GATA1 played an integral role in the fate determination of myeloerythroid lineage during embryogenesis [19]. Chan et al. found that reduced hematopoiesis in Choonodraco hamatus was associated with miR-152-mediated downregulation of GATA1 [16]. More importantly, studies have found abnormal localization of P-selectin induced by GATA1 (low) mutations, and increased pathological interactions with leucocytes as well, which were responsible for increased thrombosis in mice [20].

Carassius auratus red var. fulfills our basic requirements of experimental animals. It is convenient for artificial breeding, easy to discover and eliminate mutant individuals, and highly sensitive to NP $[21,22]$. C. auratus red var. embryos developed malformations under NP stress, such as spine curvature, tail deformity, pericardial abnormalities and thrombosis [23]. Our previous transcriptome study revealed that GATA1 expression in $C$. auratus red var. embryos was affected by NP-treatment, which may be one of the causes for embryonic malformation $C$. auratus [23]. In this study, we cloned and sequenced the full-length GATA1 cDNA in C. auratus red var., and conducted bioinformatics analysis. In addition, we used realtime fluorescence quantitative PCR (qRTPCR) to explore expression patterns of GATA1 in different tissues of $C$. auratus red var. and transcriptional changes of GATA1 after exposure to different concentrations of NP. Moreover, we measured differences in DNA methylation levels of the $C$. auratus red var. embryos between the NP treatment groups and the control ones at various developmental stages, and measured NP treatment effects on GATA1 methylation. This study investigated the expression of GATA1 gene in abnormal development of $C$. auratus red var. embryos under NP stress, and explored the relationship between thrombosis and GATA1 gene in malformed embryos. Our study provides cues for further research on the molecular mechanism of embryo development deformity in $C$. auratus red var. caused by NP.

\section{Results}

Analysis of GATA1 sequences from $C$. auratus red var The cDNA sequence of GATA1 from $C$. auratus red var. (GenBank Accession no. MT322308) is $2730 \mathrm{bp}$ in length, with an ORF of $1332 \mathrm{bp}$ encoding 443 amino acids (aa), $541 \mathrm{bp} \mathrm{5'-UTR,} 857 \mathrm{bp} 3$ '-UTR with three poly (A) signal sequences (AATAA), three RNA instability motifs (ATTTA), and a poly (A) tail. Two ZnF domains (aa 225-275, aa 279-329) were predicted in GATA1 protein (Fig. 1).

The genomic sequence of GATA1 from C. auratus red var. is $14,759 \mathrm{bp}$ in length, which contains 5 exons and 4 introns following the consensus rule of GT/AG (Fig. 2). Comparison of GATA1 genomic structures among Carassius auratus (Gene ID: 113081347), Cyprinus carpio (Gene ID: 109098530), Sinocyclocheilus rhinocerous (Gene ID: 107749468), Sinocyclocheilus grahami (Gene ID: 107581944), Danio rerio (Gene ID: 564960), Mastacembelus armatus (Gene ID: 113130813) and Monopterus albus (Gene ID: 109968602) demonstrated that the genomic structure of GATA1 from C. auratus red var. is identical to the GATA1 from other teleost fish, all consisting of 5 exons and 4 introns.

\section{Multiple alignments and phylogenetic analysis}

BLASTP analysis (Fig. 3) showed that GATA1 in C. auratus red var.shared highest similarity to CaGATA1 (99.10\%) and CcGATA1 (83.97\%), medium similarities to $\operatorname{SrGATA} 1$ (81.07\%), SgGATA1 (80.36\%), DrGATA1 (59.78\%), and ChGATA1 (39.6\%), and lowest similarities to MaGATA1 (20.77\%) and MoGATA1 (20.77\%).

Phylogenetic analysis further supported gene homology among those species (Fig. 4). Homologous amino acid sequences of GATA1 from other teleost fish and non-fish animals were collected from NBCI to construct a phylogenetic tree, which indicated that these homolog proteins could be divided into five groups, representing 
1 ctccttttgtgctccacaaaagaaagtcatacaggtttggaaaggcattggggtgagtgatgtgtttcgattattttcatattttaagtt

91 tttttaaattgagttttatatgccttatactttaagtataattgtaaaatagtttaaagctaatatttgagaatttactcaaatgttctt 181 gatgaattaggttcaacttccacatagaaacctttctgtgttttagcagatctaaaattagattttggtctttatactgtatgttggca 271 ttgcatattgtaattctcatttgcatgtggcatatttccagacttttttgtgcatttgaactttgagacacaccatttgctgaagctg 361 acctgtttgtggctccgcccactgtccccacatgtctaacctcaatcacccactatgccagagcacagaatcttcacatcttcataaag 451 ttctgaccatcagcggtgctcattttcgtcacagacacctgtcctgaagaccgaactgataagctcagtacaaaaggagttcctgacaga $\begin{array}{lllllllllllllllllllllllllllllllll}1 & M & E & T & S & T & E & Q & A & R & W & V & S & S & S & M & V & S & S & E & V & M & P & N & Y & P & P & D & S & S & Y\end{array}$ 541 CATGGAGACCTCCACTGAACAGGCTCGCTGGGTTTCCTCCTCCATGGTATCATCAGAGGTGATGCCCAATTACCCACCTGACTCCAGCTA

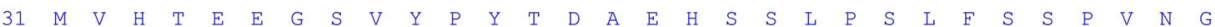
631 TATGGTCCACACTGAGGAGGGTTCAGTGTACCCCTACACCGATGCCGAACACAGCAGCCTGCCCTCTTTATTCAGCAGCCCTGTCAATGG

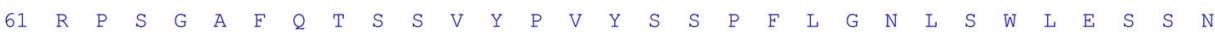
721 TCGTCCATCTGGAGCTTTCCAAACCAGCTCAGTATATCCCGTTTACTCTTCTCCATTCCTGGGAAACCTGTCCTGGCTGGAAAGTTCGAA

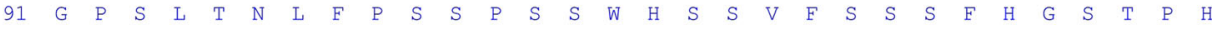
811 CGGCCCATCTCTAACCAACCTCTTCCCATCCTCCCCATCATCCTGGCACAGCAGTGTGTTTTCCTCATCCTTCCACGGCTCCACGCCTCA

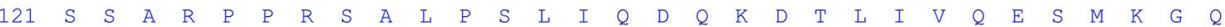
901 CTCCTCTGCCAGACCGCCTCGTTCTGCCCTTCCCTCCCTTATCCAGGACCAGAAGGATACCCTTATTGTGCAGGAGAGCATGAAAGGACA

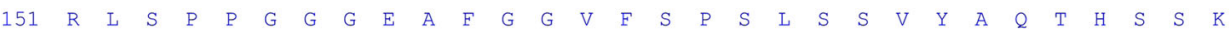
991 GAGGCTGAGTCCTCCTGGAGGAGGGGAGGCGTTTGGTGGTGTGTTTTCCCCCTCATTGAGCAGTGTGTATGCGCAGACACACTCCTCAAA

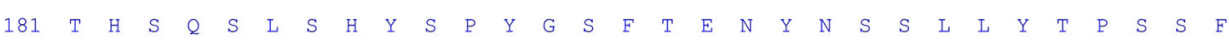
1081 AACACACTCGCAGTCACTGAGCCACTACAGTCCCTATGGGAGCTTCACGGAGAACTACAACAGTTCACTTCTCTACACACCCTCGTCCTT

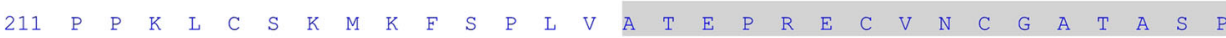
1171 CCCACCCAAATTATGCAGCAAGATGAAATTCTCTCCTTTAGTGGCGACAGAGCCGCGTGAGTGTGTGAACTGTGGGGCCACTGCATCCCC $\begin{array}{lllllllllllllllllllllllllllllllllllll}241 & L & W & R & R & D & G & T & G & H & Y & L & C & N & A & C & G & L & Y & H & K & M & N & R & Q & N & R & P & L & I & R\end{array}$ 1261 TCTGTGGCGGCGTGATGGAACGGGACACTACCTCTGCAATGCCTGCGGTCTGTACCACAAGATGAATAGACAGAACAGACCCCTCATCCG $\begin{array}{llllllllllllllllllllllllllllllllllllllllll}271 & P & K & K & R & L & V & I & S & K & R & T & G & T & Q & C & V & N & C & Q & T & S & T & T & T & L & W & R & R & N & A\end{array}$ 1351 ACCCAAAAAGAGACTGGTCATCAGTAAGCGAACAGGAACTCAATGTGTGAACTGTCAGACCAGCACCACCACGCTGTGGAGACGAAACGC

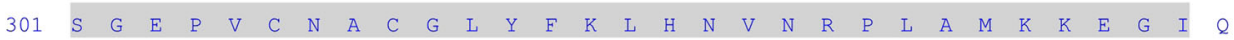
1441 CAGTGGAGAGCCCGTGTGTAACGCTTGCGGACTCTATTTCAAGCTTCACAATGTGAACAGGCCGCTCGCTATGAAGAAGGAAGGCATCCA $\begin{array}{llllllllllllllllllllllllllllllllllll}331 & T & R & N & R & K & M & S & S & K & N & R & K & G & K & K & F & S & P & T & E & E & N & L & Y & E & S & K & N & P & G\end{array}$ 1531 GACGCGCAACCGTAAGATGTCCAGCAAGAACAGGAAAGGGAAGAAGTTTAGCCCCACAGAGGAGAATCTATATTTTTCAAAGAATCCTGG

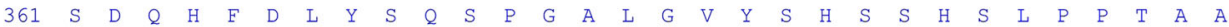
1621 ATCTGATCAGCATTTCGACTTGTATTCTCAGAGTCCAGGAGCTCTGGGCGTCTACAGCCACTCATCCCATTCACTGCCGCCCACCGCTGC

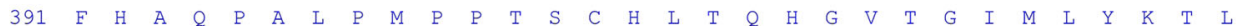
1711 CTTCCACGCCCAGCCTGCTCTACCCATGCCACCCACCAGCTGCCATCTTACCCAGCATGGTGTGACGGGAATCATGTTGTACAAAACACT

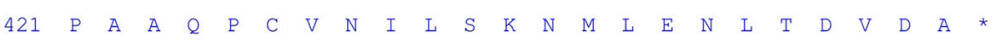
1801 CCCAGCTGCCCAGCCATGTGTTAACATACTCAGTAAAAACATGCTTGAAAACTTAACAGATGTGGATGCATGAaaaaaacatgttgccct 1891 aaaaatatttggatgctttagtcacacgatgtcggaatctcaatccactgtgtagaaaacatcaaatcatgtgcgtttattttaaagaaa 1981 gacagaacaaacccactttacaagtttgctagatttgaaagcttgaaagattaaaactattatgaagcatatggtaaagcgttagtgga 2071 acatgtcctcagttataaagctacatgaacattttggcaaaggtttggggtttccgaaaggttttttaaagaattaatacttctattca 2161 gcaaggatgcattagattgatcaaagtgactgtaaagacatttacaatgttacaaaatactgttcttttgacctttttatccagccaa 2251 aaaagtattgcaatgtaaagcagcaaaactatttcaacatggataataatcagaaatatttcttgacaaagcaatgatttctgaagatc 2341 atgtgatgctgaagactagagtattgatgctcaaattcagctttgcatcatagcagtaaattgcaatttaaatatattcaaatagaaa 2431 acagttattttaagtagtaataatatttcacataattacagtttttactctattttctgatcaaatatatgcagcctcggtgagcagaag 2521 agatttctttcaaaaaccaacaccaaacttttatgtgattgtgtatatatagactgtcttcagtgtttttgtgtttgtaatcacttttct 2611 atatctttctttaacacttttctttgtgaacgtgtacactgtttttaaaatgttgtatggaaagaatgcagtttacaaataaacatttt 2701 tgtaaagcgaaaaaaaaaaaaaaaaaaaa

Fig. 1 (See legend on next page.) 
(See figure on previous page.)

Fig. 1 Nucleotide and putative amino acid sequences of GATA1and its product. The sequences numbers of nucleotide (lower row) and putative amino acid (upper row) are shown on the left. The translation initiation codon (ATG), stop codons (TGA) are in bold and yellow background. The motif associated mRNA instability (ATTTA) is doubly underscored, and poly-adenylation signal sequence (AATAA) is emphasized by wavy line. The $\mathrm{ZnF}$ domains are marked with gray background

mammals, birds, amphibians, fishes and invertebrates, respectively. The phylogenetic tree revealed that the GATA1 protein in C. auratus red var. is closest to of its ortholog in $C$. auratus, with a high bootstrap value of 99\%. All the fish GATA1 proteins clustered together, and diverged from their counterparts in other groups. GATA1 proteins in invertebrates were far separated from those in vertebrates. Thus, the phylogenetic tree reflected a genetic consistency among those species in evolution.

\section{Distribution of GATA1 in C. auratus red var. tissue}

qRT-PCR was performed to analyze the tissue distribution of GATA1 mRNA expression. As shown in Fig. 5, GATA1 expression was detected in all organs tested, and the values were calibrated against the expression level in heart $(\mathrm{H})$. GATA1 had the highest expression level in testis $(\mathrm{T})(100.44$ folds, $P<0.05)$; intermediate levels in pituitarium (P) (7.91 folds, $P<$ 0.05), spleen (S) (5.70 folds, $P<0.05)$, gills (G) $(3.90$ folds, $P<0.05)$, brain (B) $(3.43$ folds, $P<0.05)$; and the lowest levels in muscle $(\mathrm{M})$ (0.68 folds), liver (L) (0.35 folds), and ovary (O) (0.33 folds).
GATA1 expression in different developmental stages after NP treatment

To determine the effect of NP exposure on GATA1 gene expression, the levels of GATA1 mRNA in different developmental stages were examined (Fig. 6). During the normal embryonic development, the GATA1 gene expression can be detected from the $\mathrm{N}$ stage, and the expression level increased at the S5 stage, decreased continuously at S14 and S21 stages, and then increased again at the P5 stage. Afer that, it reached to the highest at the P25 stage, and dropped again after embryo hatching. GATA1 expression levels in both the $3 \mu \mathrm{mol} / \mathrm{L}$ and $5 \mu \mathrm{mol} / \mathrm{L}$ NP-treated groups showed the biggest difference from that in the control group at the S14 stage, while the biggest difference in GATA1 expression between the $7 \mu \mathrm{mol} / \mathrm{L}$ NP-treated and control groups happened at S21 stage. (Fig. 6). On the other hand The biggest difference in GATA1 mRNA levels at the neuroblast stage was found between the control and the $3 \mu \mathrm{mol} / \mathrm{L}$ NP treated groups when compared with other group pairs. When embryos developed to the 5 somite stage, the $7 \mu \mathrm{mol} / \mathrm{L}$ NP-exposure group had greater effect on the expression of GATA1 gene than other treated groups with lower NP dosages (Fig. 6).

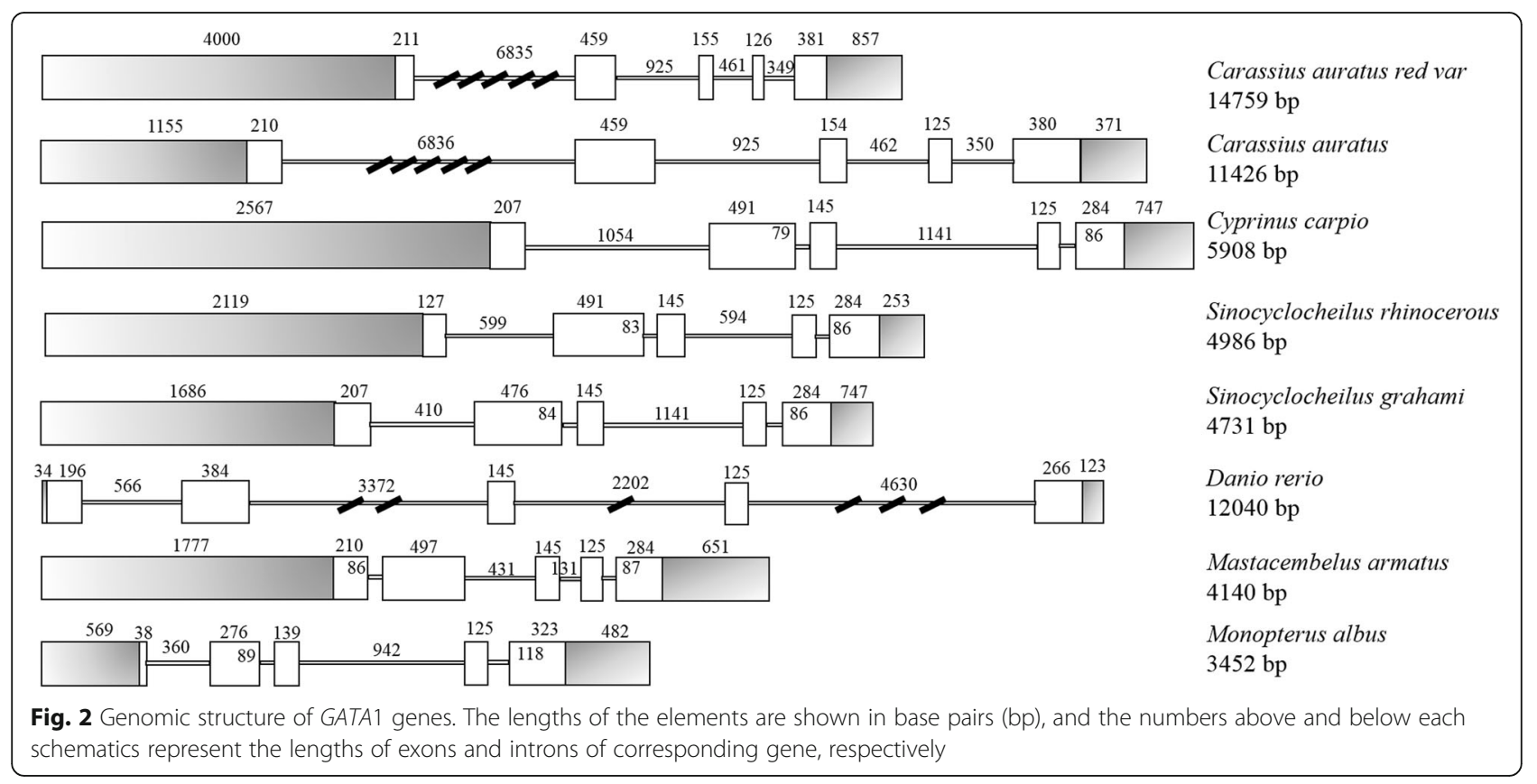


GATA1

CaGATA1

CCGATA1

SrGATA1

SgGATAI

DrGATA1

ChGATA1

MaGATA1

MOGATA
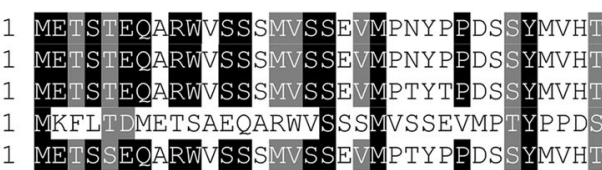

11:19

inii

EEGSVIVITIDADHSTIPS ESS

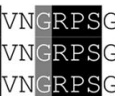

醩

1

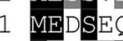

1

MTAQSEASR

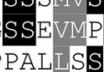

LLHGEEAS I FPCTDADHS GLPSLFSSPVH

SPVNGRPSGAEQTSSVY PVYSSPIL RPAAFQHSPVYPIYSSPFLGNLSW S SHSRAPPTYR SSVRQVE SSP IN
INIKGSAPSQTLFQSPNPAHDACHRVTSPCLWLDDSGHQSLSSDSIPPPPSPSLYGNPALTPPCSCILSS

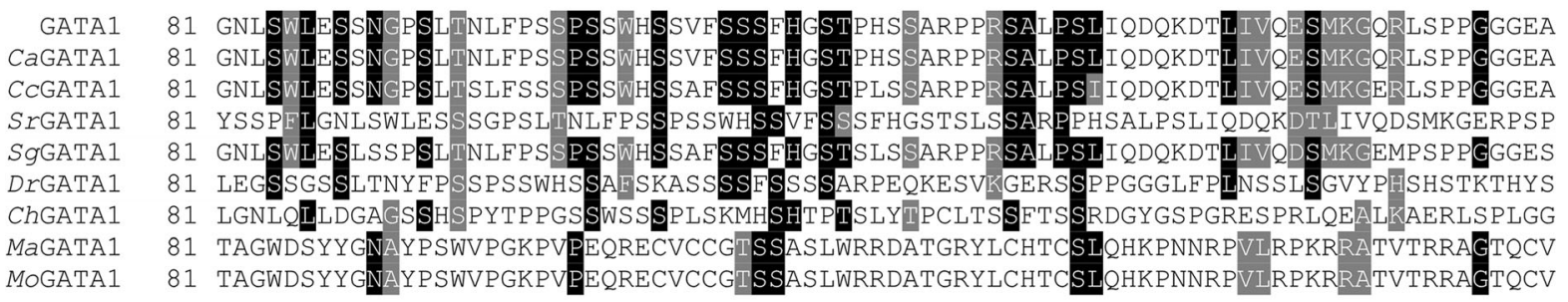

GATA 1 CaGATA CCGATA SrGATA SgGATA DrGATA ChGATA MaGATA MOGATA

\section{FGGVESPSLSSVYAOTHSSKTHSOSLSHYSPYGS} 161 FGGVESPSLSSVYA QTHSSKMHSQSLSHYSPYGS 161 FGGVESPSVSSVYAQTHSSKTHSQSLSHYSPYGS

\section{PGGGESFGGVFSPSV}

VSIVYAQTHSSK SQSLSHY

\section{ENYNSSIIYTPS
ENYNSSI LYTPS
QDYNSSILYTPS \\ PYGSFTQDYSSSILY}

FPPRLCSKMKFSPLVATEPRECVNCGATASP 61 FGSVFSPSVSSVYAQTHSSKTHLQSLS LYTPSSFSPNLCSKMKFSPLEPRECVNCGAT

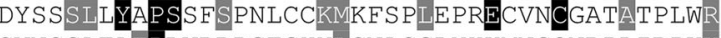
61 SGVSS QDYSSSLLYAPA FIPKLCSKMNF SPDARECVNCGATATPLWRRDGTGHYLCNACGLYHKMNGQNRPLIRPKK 161 NCETVTTILWRRNA G GQVCNACGLYYKLHRVNRPLTMKREEIQTRNRKVINKNKKRISGAKSETEWCWLASPTDEAILH 161 NCETVMTTLRRNAAGQPVCNACGLYYKLHRVNRPLTMKREEIQTRNRKVMKNKKRISGAKSETEWCWLASPTDEAILH

GATA1 241 LWRRDTGHYLCNACGLYHKMNRQNRPLIRPKKRLVISKRTGTOCVNCQTSTTTWWRRASGEPVCNACGLYFKUHNVNR CaGATA1 241 LWRRDGTGHYCNACGLYHKMNRQNRPLIRPKKRLVISKRTGTQCVNCOTSTTTLWRRNASGEPVCNACGLYFKLHNVNR CCGATA1 241 RDGTGHYLCNACGLYHKMNGQNRPLIRPKKRLVISKRTGTQCANCQTSTTILWRRNASGEPVCNACGLYFKLHNVNRPLA SrGATA1 241 ATPLWRRDGTGHYLCNACGLYQKMNRQNRPLIRPKKRLVISKRTGTQCANCQTSTTTLWRRNAGGEPVCNACGLYFKLHN SgGATA1 241 RDGTGHYLCNACGLYHKMNGQNRPLIRPKRRLVISKRTGTQCANCQTSTTILWRRNAGGEPVCNACGLYFKLHNVNRPLA DrGATA1 241 RPVVSKRIGTOCANCOTSTTTLWRRNSSGEPVCNACGLYFKLHNVNRPLAMKKEGIQTRNRKVSSKNRKGKKFSTMEENL ChGATA1 241 LWRRDGTGHYLNACGLYHKMNGQNRPLIRPKKRLIVSKRAGTVCANCHTSTTTIWRRNASGEPVCNACGLYFKUHNVNR MaGATA1 241 SETHLPPTPLCSWPRSAGHDQSHWESPAGTISCPRAESRATLRPERSAEVRGGGIHGC---------- - - - - - - MOGATA1 241 SETHLPPTPLCSWPRSAGHDQSHWESPAGTISCPRAESRAMLRPERSAEVRGGGIHGC-

GATA1 321 PLAMKKEGIOTRNRKMSSKNRKGKKFSPTEENLYFSKNPGSDQHFDLYSQSPGALGVYSHSSHSLPPTAAFHAQPALPMP CAGATA1 321 PLAMKKEGIOTRNRKMSSKNRKGKKFSPTEENLYFSKNPGSDQHFDLYSQSPGALGVYSHSSHSLPPTAAFHAQPALPMP CCGATA1 321 MKKEGIQTRNRKVSSKNRKGKKESATEENLYFSKNPASDQHFDLYSQSPGALGIYSHSSHSLPPTAAFHSHASLPYPYHP SrGATA1 321 VNRPLAMKKKGIQTRNRKVSSKNRKGKKFSATEENLYFSNNPSSDQHFDLYSQSPGALGIYSHSSHSLPPTAAFHSHASL SgGATAI 321 MKKEGIQTRNR RVSSKNRKGKKFSATEENLYFSKYPSSDQNFDLYSQSPGALGVYSHSCHSLPPTAAFHSHASLPYPYHP DrGATA1 321 YCDFPKTPACDOHFDMYSOSPAALGVYSHSGQSTAYLPYPYHSSPAVLPSTV $-\ldots-\ldots-\ldots$ ChGATA1 321 PLAMKKEGIQTRNRKVSKNKKSKKVAMFESYSDGPQPMDDCGPYSLGPGSLLSYSHAPHLMPTPQPLHPSHSFQYTHHL

Fig. 3 (See legend on next page.) 
(See figure on previous page.)

Fig. 3 Multiple alignments of GATA1 with GATA1 proteins from various species. The amino acid sequences of GATA1 from typical organisms were aligned using the ClustalW 2.1 program. The black shade represents 100\% identity, dark gray represented 80\% identity. CaGATA1 stands for GATA1 protein in Carassius auratus (Protein ID. XM_026253445.1), CCGATA1 stands for GATA1 protein in Cyprinus carpio (Protein ID. XM_019103428.1), SrGATA1 stands for GATA1 protein in Sinocyclocheilus rhinocerous (Protein ID. XM_016537268.1), SgGATA1 stands for GATA1 protein in Sinocyclocheilus grahami (Protein ID. XM_016271639.1), DrGATA1 stands for GATA1 protein in Danio rerio (Protein ID. XP_021334219.1), ChGATA1 stands for GATA1 protein in Chionodraco hamatus (Protein ID. KP221299.1), MaGATA1 stands for GATA1 protein in Mastacembelus armatus (Protein ID. XP_026189425.1), MoGATA1 stands for GATA1 protein in Monopterus albus (Protein ID. XM_020614979.1)

Apparently, NP affected GATA1 expression during the development of $C$. auratus red var. embryos, and the greatest effect took place in somatic embryos.

The methylation levels of GATA1 changed significantly in NP -treated groups

Our selected GATA1PCR target fragment was $277 \mathrm{bp}$ in size and had $10 \mathrm{CpG}$ sites. Table 1 shows the methylation status of $10 \mathrm{CpG}$ sites in the control and NP5 treatment groups. In the control groups, the methylation rates of GATA1 gene at N, S5, S14, S21, P5, P25 and $\mathrm{H}$ stages were $85.88,94.33,92.86,89.61$, $92.67,98.00$, and $89.33 \%$, respectively. While in the NP-treated groups, the methylation rates of GATA1 gene at N, S5, S14, S21, P5, P25 and H stages were 93.52, 96.67, 98.00, 97.06, 98.00, 98.67, and 97.00\%, respectively (Fig. 7). Obviously, methylation levels of GATA1 gene in the NP-treated embryo groups were mostly higher than that in the control group. We analyzed correlation between GATA1 mRNA expression and methylation of GATA1 gene in both the control

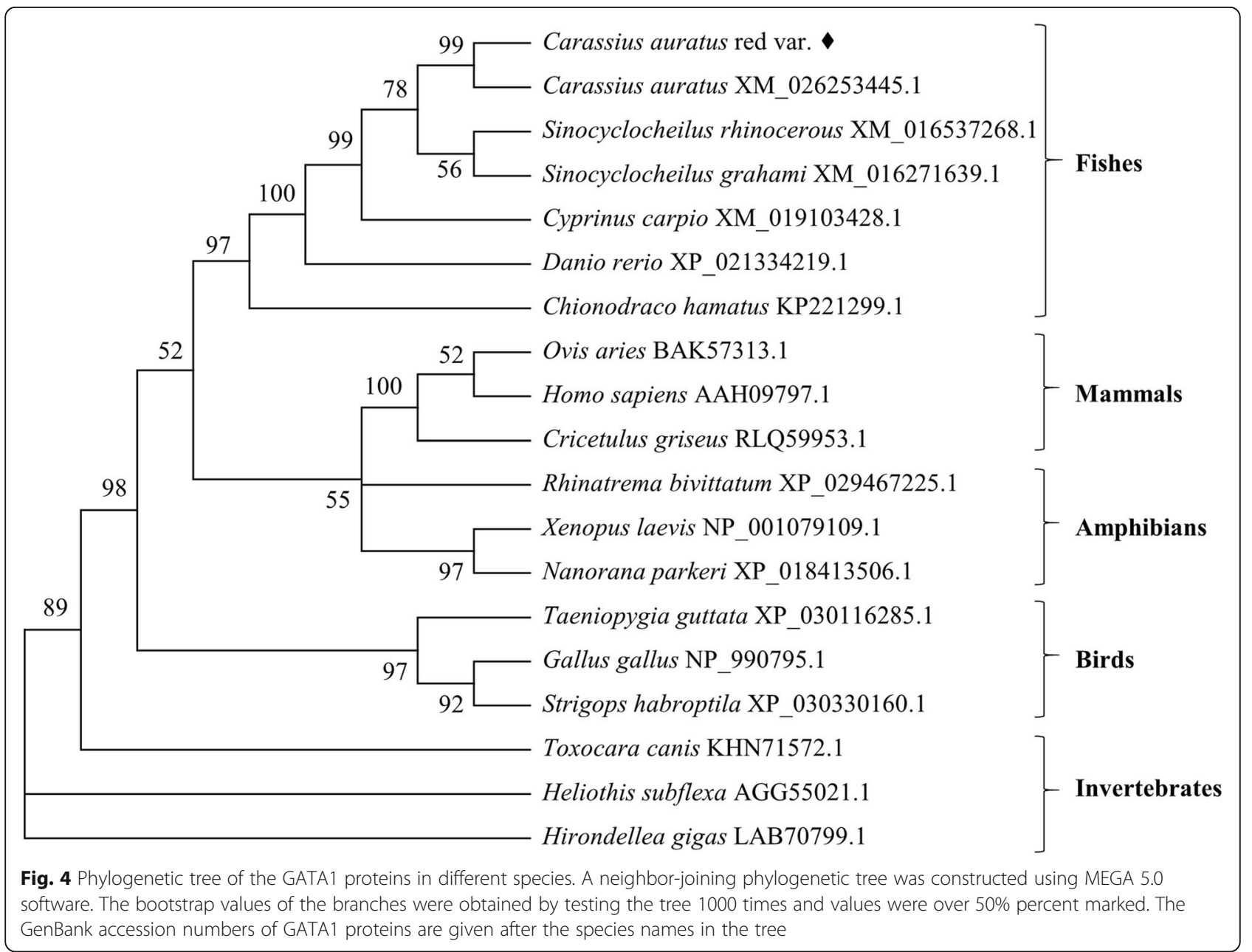




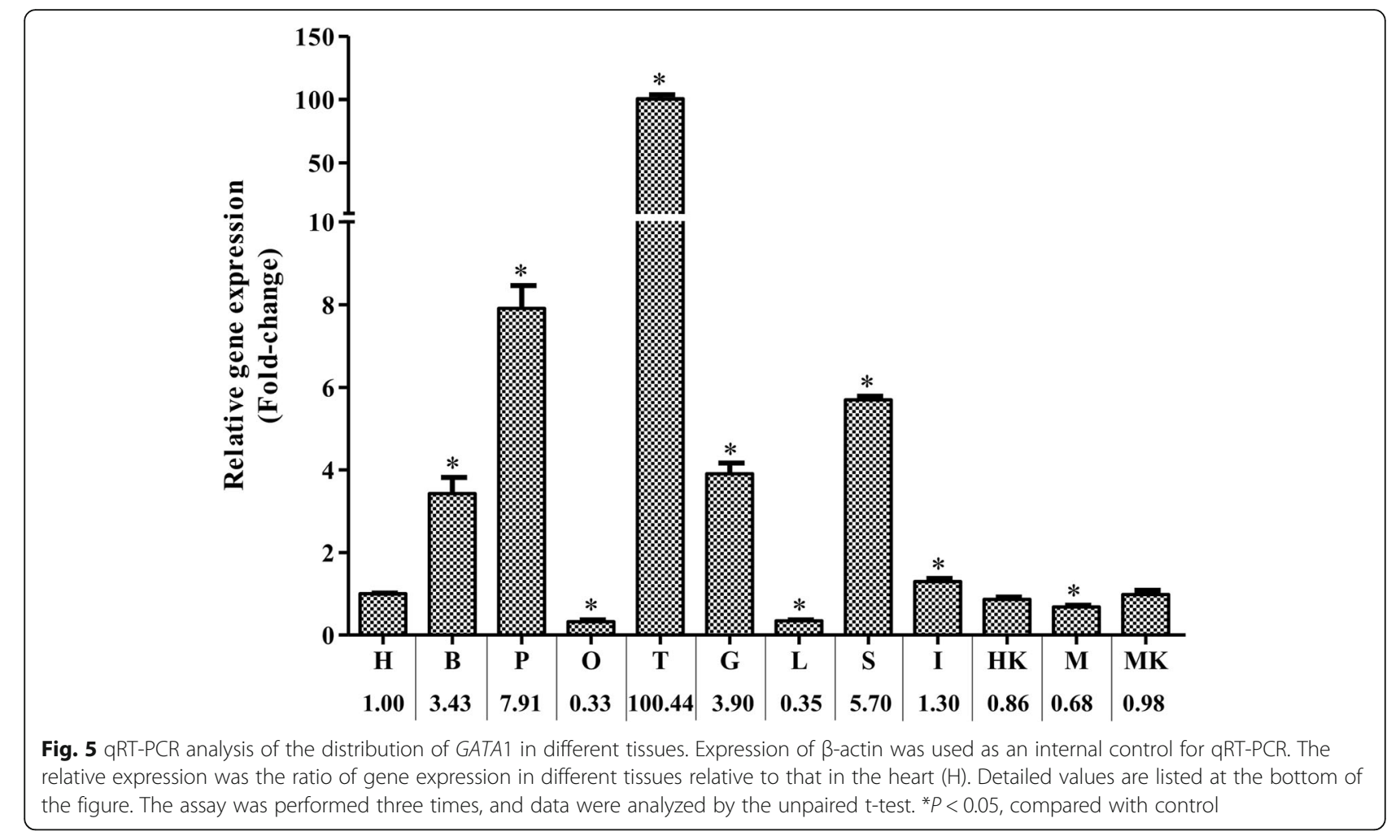

and NP-treated groups, and found GATA1 expression was significantly positively correlated with its methylation level in the control group $(r=0.771, P<0.05)$, but not in the NP-treated groups $(r=0.533, P>0.05)$.

\section{Discussion}

In this study, $C$. auratusthe full-length GATA1 cDNA sequence was obtained from $C$. auratus red var. by homologous cloning and RACE Technologyc. auratus. GATA1 cDNA is $2730 \mathrm{bp}$ in length with a $1332 \mathrm{bp}$ long ORF encodeing 443 amino acids (aa) a $541 \mathrm{bp}$ long 5'-UTR and an 857-long bp 3'-UTR. C. auratus red var. is a variant of Carassius auratus. Alignment analysis revealed that the similarity between the $C$. auratus red var. GATA1 and C. auratus GATA1 protein was as high as $99.1 \%$. Also, phylogenetic analysis

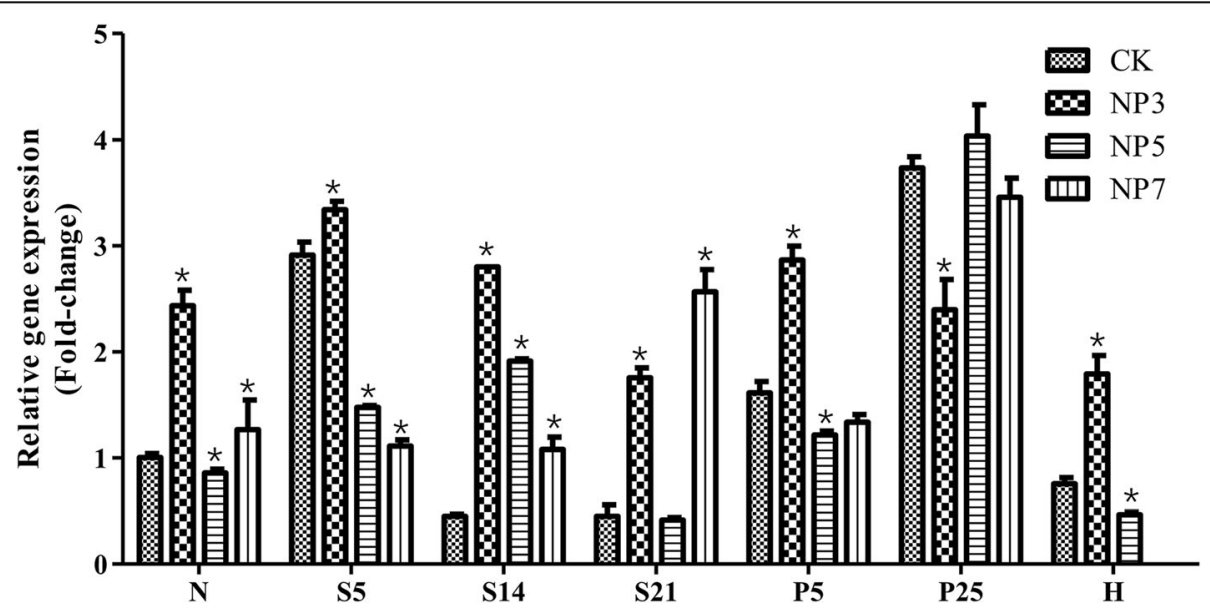

Fig. 6 Expression levels of GATA1 in the treatment and control groups at various developmental stages. CK: 0 mol / LNP-treated embryos; NP3: $3 \mu \mathrm{mol} /$ LNP-treated embryos; NP5: $5 \mu \mathrm{mol} /$ LNP-treated embryos; NP7: $7 \mu \mathrm{mol} /$ LNP-treated embryos. C. auratus red var. embryos mostly failed to hatch under NP7 treatment, so no $\mathrm{H}$ stage samples were collected. The data between different treatment groups at the same developmental period were analyzed by the unpaired t-test. ${ }^{*} P<0.05$, compared with control 
Table 1 Methylation status of the 5'UTR region of the GATA1 gene

\begin{tabular}{lll}
\hline CpG sites & Methylation level of the CK/\% & Methylation level of NP5/\% \\
\hline-3681 & 100.00 & 100.00 \\
-3668 & 100.00 & 100.00 \\
-3657 & 97.94 & 100.00 \\
-3528 & 86.60 & 96.08 \\
-3518 & 79.38 & 97.06 \\
-3490 & 60.82 & 69.61 \\
-3478 & 89.69 & 97.06 \\
-3466 & 98.79 & 100.00 \\
-3434 & 100.00 & 100.00 \\
-3413 & 100.00 & 100.00
\end{tabular}

The CpG sites were located between $-3413 \sim-3681$ upstream to the start codon

CK: $0 \mu \mathrm{mol} /$ LNP-treated embryos; NP5: $5 \mu \mathrm{mol} /$ LNP-treated embryos

Degree of methylation = methylation number of the measured $\mathrm{CpG}$ sites/total number of the CpG sites measured

showed that the GATA1 protein in C. auratus red var. was closest to that in C. auratus, with bootstrap values reaching $99 \%$. The high similarity between the C. auratus red var. and C. auratus amino acid sequences is in line with our expectations. In vertebrates, members of the GATA family generally consist of five or six exons and include two conserved type IV zinc finger domains: an amino terminal zinc finger $(\mathrm{N})$ and a carboxyl terminal one $(\mathrm{C})$ [24]. We analyzed the conserved domains in the predicted GATA1 protein with SMART, and found that the $C$. auratus red var. GATA1 contains two $\mathrm{ZnF}$ domains (aa 225-275, aa 279-329); The C. auratus red var. GATA1 gene consists of five exons, which is consistent with its paralogs in other species.
The tissue distribution of GATA1 mRNA was analyzed through qRT-PCR. GATA1 expression was detected in all tested tissues of $C$. auratus red var. GATA1 had the highest expression level in testicle $(T)$; intermediate levels in pituitarium $(\mathrm{P})$, spleen $(\mathrm{S})$, gills $(\mathrm{G})$, brain $(\mathrm{B})$; and lower levels in muscle $(\mathrm{M})$, liver $(\mathrm{L})$, and ovary $(\mathrm{O})$. GATA1 is abundantly transcribed in mouse testis and regulates genes involved in the earliest stages of spermatogenesis [25]. Studies have shown that spermatogenesis is induced by GATA-1 expression in Sertoli cells. As atranscription factor, GATA-1 is a developmental stageand spermatogenic cycle-specific regulator of gene expression in Sertoli cells [26]. In sexually mature C. auratus red var. individuals used in this study, the GATA1 expression is most enriched in the testes among all

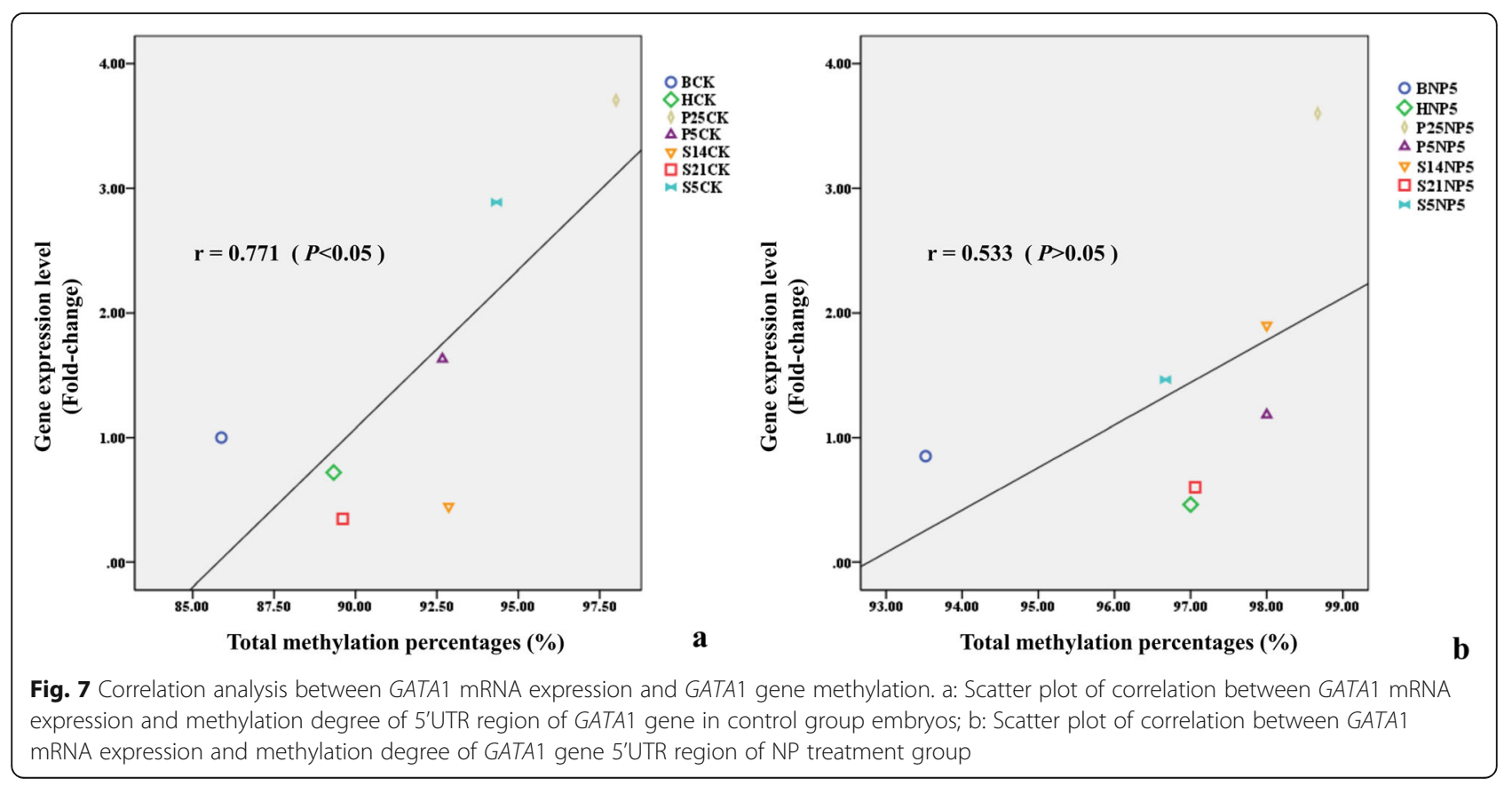


tissues and organs. The GATA transcription factor family is essential for pituitary cell differentiation and gonadotropin subunit expression [27]. GATA1 inhibits formation of rat cortical neurons, and GATA1 overexpression ofin the hippocampus can cause depressive behavior in rats [28]. Spleen is an important hematopoietic organ in animal bodies, and the gills are the respiratory fish organs with a large number of capillaries. Accordingly as a key regulator of red blood cell production [18], the GATA1 gene is expressed at high levels in $\mathrm{P}, \mathrm{S}$, $\mathrm{G}$, and $\mathrm{B}$ of $C$. auratus red var. We also found very low GATA1 expression in $\mathrm{L}$ and $\mathrm{O}$ of $C$. auratus red var. which was consistent with a report in Nile tilapia (Oreochromis niloticus) [29]. C. auratus. Thus, our results with GATA1 expression pattern in various tissues and organs $C$. auratus provided essential cues to understand GATA1 functions in C. auratus red var. adults.

In $C$. auratus red var. embryos, the GATA1 gene starts to be detectable from the neural embryo stage, and stays continuously expressed during embryonic development with relatively stable expression levels, which indicates that GATA1 is involved in the entire embryonic development of $C$. auratus red var. GATA1is also involved in early embryonic development in other fish. In general, early blood islands emerged in the yolk sac endoderm and splanchnic mesoderm during early embryonic development. GATA expression became detectable in zebrafish ectoderm $9 \mathrm{~h}$ after fertilization [30]. In Branchiostoma belcheri, GATA1 expression signal could also be detected at the mesendoderm of gastrula stage [31]. NP affects GATA1 expression during the development of $C$. auratus red var. embryos, $C$. auratus with a strongest effect at the somatic stage, and with a most effective NP concentration at $3 \mu \mathrm{mol} / \mathrm{LC}$. auratus. During vertebrate early embryogenesis, the ventral development is directed by the ventral-to-dorsal activity gradient of the bone morphogenetic protein (BMP) signaling [32]. Abnormalties in the BMP signaling pathway may cause strong dorsalization phenotypes in embryos [33]. GATA1 gene is a downstream target of the BMP signaling pathway [34], and is shown to exert repressive effects on spine formation in cortical neurons [35]. Under NP stress, the abnormal expression of GATA1 gene in $C$. auratus red var. embryos may count for dorsalization after NP treatment. The transcriptional activity of GATA1 is related to the expression level of vitellogenin $(V g)$ [36]. $V g$ expression measurement has been used as a biomarker of exposure to endocrine-disrupting chemicals [37]. Up-regulation of GATA1 expression in C. auratus red var. embryos under NP exposure may increase $V g$ expression, further proving NP is an environmental endocrine disruptor. Yokomizo et al.'s experiments in mouse embryos provided evidence showing the presence of GATA-1(+) hemangioblastic cells in the extra-embryonic region, demonstrating that the GATA1 is involved in definitive hematopoiesis at embryonic stage in close association with endothelial development [38]. GATA1 or GATA2 is required to initiate blood production in the embryo, so GATA1 and GATA2 double deficient mice exhibit no visible blood cells [39]. In addition, GATA1 mutations lead to increased thrombosis in mice [20]. Therefore, the occurrence of thrombosis in C. auratus red var. embryos under NP stress may be related to down-regulation of GATA1 gene expression.

DNA methylation is a heritable modification that affects gene expression without changing DNA sequences. This modification is crucial to embryonic development. Either abnormally higher or lower methylation levels could be detrimental to the normal growth and embryonic development [40]. Reduced methylation on H3-K4 in Lsd1 mutant fruit flies results in tissue-specific developmental defects [41]. Compared with that in normal embryos, $H 19$ gene methylation is severely altered in abnormally developing embryos [42]. In offspring of vitamin-deficient rats, the embryos showed a higher incidence of heart defects, possibly due to the high methylation level of the GATA4 gene [43]. In this study, we found that the methylation level of GATA1 in the control group was lower than that in the NP-treated $C$. auratus red var. embryos, which demonstrates that NP stress increases methylation level of GATA1 in C. auratus red var. during embryonic development. GATA1 expression is significantly positively correlated with its methylation level in the control group, but not in the NP-treated group. In addition, high levels of GATA1 expression during the same developmental period are not necessarily low in methylation level. Since GATA1 expression levels at different developmental stages in the control group were apparently correlated with GATA1 methylation levels, we suspected that NP exposure affected GATA1 expression through changing its methylation status. However, due to the lack of correlation between GATA1 expression and its methylation in the NP-treated groups, other mechanisms must have been involved. C. auratus This is similar to what Okada et al. reported in mice. In $3 \mathrm{~T} 3-\mathrm{L} 1$ preadipocytes, demethylation did not increase leptin gene expression, and the diet-induced up-regulation of leptin, Mest/Peg1, and sFRP5 gene expression in white adipose tissue (WAT) during the development of obesity in mice is not mediated directly by changes in DNA methylation [44]. In addition, when studying the effect of monomeric and oligomeric flavanols (MOF) consumption on the gene expression profile of leukocytes, Milenkovic et al. found that daily supplementation with $200 \mathrm{mg}$ MOF for 8 weeks modulates the expression of genes associated with cardiovascular disease pathways without major changes of their DNA methylation status [45]. 


\section{Conclusions}

In this study, the full-length cDNA sequence of GATA1 gene in $C$. auratus red var. was cloned, and the special and temporal expression patterns of GATA1 gene in various tissues/organs and embryonic developmental stages of $C$. auratus red var. were analyzed. Changes in GATA1 expression during NP-stressed embryonic development was measured, which revealed a role of NPstress in regulation of GATA1 expression. It provides important cues for unravel GATA1 functions in fish development and molecular mechanisms through which NP leads to abnormal development in fish embryos.

\section{Methods}

\section{Fish and sampling}

Two-year-old healthy $C$. auratus red var., weighting about $200 \pm 10 \mathrm{~g}$ with an average length of $15 \pm 3 \mathrm{~cm}$, were obtained from the Engineering Research Center of Polyploid Fish Breeding and Reproduction of the State Education Ministry at Hunan Normal University. All experiments performed were approved by the Animal Care Committee of Hunan Normal University. Before experiments, the fish were acclimatized in an indoor freshwater tank at $25 \pm 1{ }^{\circ} \mathrm{C}$ and fed twice daily with a commercial diet for 1 week. After no abnormal symptoms were observed, the $C$. auratus red var. were subjected to further study.

Three healthy fish were sacrificed as one group, and samples from the gills $(\mathrm{G})$, liver $(\mathrm{L})$, spleen $(\mathrm{S})$, intestines (I), middle kidney (MK), muscle (M), head kidney (HK), heart $(\mathrm{H})$, brain $(\mathrm{B})$, pituitarium $(\mathrm{P})$, and gonads (testis $(\mathrm{T})$ or ovary $(\mathrm{O})$ ) were collected, respectively. All samples were immediately homogenized in TRIzol reagent (Invitrogen, USA) and stored at $-80^{\circ} \mathrm{C}$ until RNA extraction. At the same time, fin tissues were isolated and fixed in $95 \%$ ethanol. To minimize suffering, $100 \mathrm{mg} / \mathrm{L}$ MS-222 (Sigma-Aldrich, St Louis, MO, USA) was used to anaesthetize fish before dissection.

\section{NP treatment}

NP was used for challenge experiments. All the embryos 2 min after fertilization were exposed to NP with the concentrations of $0 \mu \mathrm{mol} / \mathrm{L}$ (blank control, $0.01 \%$ etha$\mathrm{nol}), 3 \mu \mathrm{mol} / \mathrm{L}, 5 \mu \mathrm{mol} / \mathrm{L}$ and $7 \mu \mathrm{mol} / \mathrm{L}$, respectively. Each group was employed for 5 parallel repetitions. Embryo incubation and NP exposure were carried out in $25 \mathrm{~cm}$ glass at $25 \pm 1^{\circ} \mathrm{C}$.

Intact embryos were collected at 7 stages: neuroblast stage (N), 5 somite stage (S5), 14 somite stage (S14), 21 somite stage (S21), pharyngeal stage-primordium-5 (P5), pharyngeal stage-primordium-25 (P25) and hatching stage $(\mathrm{H})$ after NP exposure. Six groups with 30 embryos in each group were collected at each time points and we used liquid nitrogen to stop embryo development.
Samples within each group were homogenized, and aliquots of homogenized tissues were taken for DNA and RNA isolation, respectively.

\section{RNA extraction and CDNA synthesis}

The total RNAs were extracted according to the manufacturer's instruction for TRIzol reagent. Later, the RNA samples were incubated in RNase-free DNase I (Promega, USA) to eliminate any contaminating genomic DNA. Random primers and a ReverTra Ace kit (Toyobo, Japan) were used for reverse transcription to generate cDNA. Samples that need to be extracted total RNAs include: various tissues of healthy adult fish, embryos of the treatment group and the control group at different developmental stages. SMART ${ }^{\mathrm{Tm}}$ RACE cDNA Amplification Kit (Takara, Japan) was used to obtain 5'-RACE Ready cDNA and 3'-RACE Ready cDNA.

\section{Full-length cDNA cloning and analysis}

To identify the cDNA sequence of GATA1 from C. auratus red var., primers GATA1-F1/R1 (Table 2) were designed and synthesized based on the highly conserved regions of known fish GATA1 sequences, including Carassius auratus GATA1 (CaGATA1, Accession no. XM_ 026253445.1) and Sinocyclocheilus rhinocerous GATA1 (SrGATA1, Accession no. XM_016537268.1). The 5' and 3' untranslated regions (UTRs) were obtained according to the manufacturer's instruction for SMART ${ }^{\mathrm{ma}}$ RACE cDNA Amplification Kit. The full-length cDNA sequences were amplified by PCR using GATA1-F2/R2 primers (Table 2) within the 5 ' and 3'UTRs, respectively.

Sequence Manipulation Suite (STS) (http://www.biosoft.net/sms/) was used to analyse the sequences of GATA1 from C. auratus red var.. The BLASTP program (https://blast.ncbi.nlm.nih.gov/Blast.cgi) was used to search for GATA1 protein sequence from other species in the NCBI (http:// www.ncbi.nlm.nih.gov/). Multiple sequence alignments were performed by the ClustalX 2.1 program (http://www.ebi.ac.uk/tools/ clustalx2.1). Simple Modular Architecture Research Tool (SMART) (http://smart.embl-heidelberg.de/) was used to predict the protein domain features. A phylogenetic tree was constructed by the neighbor-joining (NJ) algorithm embedded in Mega 5.0 software (http://www.megasoftware. net/ index.html) with a minimum of 1000 bootstraps.

\section{Genomic sequence cloning}

Genomic DNA (gDNA) was extracted from the tail fin using the Universal Genomic DNA Kit (CWBio, China) according to the manufacturer's instructions. Based on the cDNA sequences of GATA1, primers (Table 3) were designed to amplify the genomic sequences gradually. Five overlapping fragments were amplified from gDNA and sequenced. 
Table 2 Primers for full-length CDNA cloning and qRT-PCR

\begin{tabular}{|c|c|c|}
\hline $\begin{array}{l}\text { Primer } \\
\text { name }\end{array}$ & Sequence $\left(5^{\prime} \rightarrow 3^{\prime}\right)$ & Application \\
\hline GATA1-F1 & GCTCCACAAAAGAAAGTCAT & $\begin{array}{l}\text { partial sequence } \\
\text { obtaining }\end{array}$ \\
\hline GATA1-R1 & ACGAGGGTGTGTAGAGAAGT & \\
\hline GATA1-F2 & CCTCAATCACCCACTATGCC & ORF qualifying \\
\hline GATA1-R2 & GTGGATTGAGATTCCGACAT & \\
\hline $\begin{array}{l}\text { GATA1-R- } \\
\text { out }\end{array}$ & $\begin{array}{l}\text { GCTCTGGCATAGTGGGTGATTGAG } \\
\text { GTTA }\end{array}$ & $\begin{array}{l}\text { 5'-Race PCR } \\
\text { amplification }\end{array}$ \\
\hline GATA1-R-in & $\begin{array}{l}\text { ATAATCGAAACACATCACTCACCC } \\
\text { CA }\end{array}$ & \\
\hline $\begin{array}{l}\text { GATA1-F- } \\
\text { out }\end{array}$ & $\begin{array}{l}\text { GGCGTCTACAGCCACTCATCCCAT } \\
\text { TCAC }\end{array}$ & $\begin{array}{l}\text { 3'-Race PCR } \\
\text { amplification }\end{array}$ \\
\hline GATA1-F-in & $\begin{array}{l}\text { GGATGCTITAGTCACACGATGT } \\
\text { CGGAAT }\end{array}$ & \\
\hline GATA1-qF & ССTССССТСССТTATCCAG & qRT-PCR amplification \\
\hline GATA1-qR & GGTAGTGTCCCGTTCCATC & \\
\hline
\end{tabular}

The 5 'unknown sequence of the GATA1 gene was obtained from the existing gDNA sequence using the Genome Walking Kit (Takara, Japan) according to the manufacturer's instructions. The gDNA sequence was confirmed by sequencing the PCR product amplified by primers (Table 4) within the $5^{\prime}$ unknown sequences.

\section{Quantification of gene expression}

qRT-PCR was carried out in StepOnePlus Real-Time PCR System (ABI, USA) to quantify the mRNA

Table 3 Primers for genomic DNA sequences

\begin{tabular}{lll}
\hline Primer name & Sequence $\left(\mathbf{5}^{\prime} \rightarrow \mathbf{3}^{\prime}\right)$ & $\begin{array}{l}\text { Product Length } \\
(\mathbf{b p})\end{array}$ \\
\hline GATA1-gDNA- & CAATCACCCACTATGCCAGAGC & $914 \mathrm{bp}$ \\
F1 & & \\
GATA1-gDNA- & GCTGAATAAAGAGGGCAGGC \\
R1 & TG \\
GATA1-gDNA- & TGGTCCACACTGAGGAGGGTTC & $1238 \mathrm{bp}$ \\
F2 & & \\
GATA1-gDNA- & GGAAACTGTGTACCAGGG & \\
R2 & ACGG \\
GATA1-gDNA- & CTGAGCCACTACAGTCCCTATG & $1172 \mathrm{bp}$ \\
F3 & & \\
GATA1-gDNA- & AGGGGTCTGTTCTGTCTATTCA & \\
R3 & & \\
GATA1-gDNA- & GATGGAACGGGACACTACCTCT & $664 \mathrm{bp}$ \\
F4 & & \\
GATA1-gDNA- & TAGAGTCCGCAAGCATTACACA \\
R4 & & \\
GATA1-gDNA- & GGAACTCAATGTGTGAACTGTC & $528 \mathrm{bp}$ \\
F5 & & \\
GATA1-gDNA- & CTGTTCTTGCTGGACATCTTAC \\
R5 & & \\
\hline
\end{tabular}

Table 4 Primers for 5'unknown sequences

\begin{tabular}{lll}
\hline $\begin{array}{l}\text { Primer } \\
\text { name }\end{array}$ & Sequence $\left(\mathbf{5}^{\prime} \rightarrow \mathbf{3}^{\prime}\right)$ & Application \\
\hline GATA1-SP1 & $\begin{array}{l}\text { CAGAGCAAGGCTGTGGAA } \\
\text { GTCATT }\end{array}$ & $\begin{array}{l}5^{\prime} \text { - Walking PCR } \\
\text { amplification }\end{array}$ \\
GATA1-SP2 & $\begin{array}{l}\text { GTCCTGGTTTGGAGGTTGTTG } \\
\text { CC }\end{array}$ & \\
GATA1-SP3 & $\begin{array}{l}\text { GCTTCCACCTTTGATAGA } \\
\text { GGCTGA }\end{array}$ & \\
GATA1-F3 & $\begin{array}{l}\text { ATGGCTGTAGTGCTCATTCATC } \\
\text { GCT }\end{array}$ & verification \\
GATA1-R3 & CAAGAGATTCACAACTATGACT & \\
\hline
\end{tabular}

expression of GATA1 in different tissues, including intestine (I), liver (L), spleen (S), gills (G), middle kidney $(\mathrm{MK})$, muscle $(\mathrm{M})$, head kidney $(\mathrm{HK})$, heart $(\mathrm{H})$, brain $(\mathrm{B})$, pituitarium $(\mathrm{P})$, testicle $(\mathrm{T})$, and ovary $(\mathrm{O})$. Specific primers (Table 2) were designed for qRT-PCR. The housekeeping gene $\beta$-actin [46] (Table 5) was utilized as an internal control for cDNA normalization, and the expression level in the heart $(\mathrm{H})$ was used as the baseline (1.0) for qRT-PCR.

To determine the effects of NP stress on GATA1 mRNA expression, the expression levels of GATA1 in different developmental stages of $C$. auratus red var. embryos (neuroblast stage (N), 5 somite stage (S5), 14 somite stage (S14), 21 somite stage (S21), pharyngeal stage-primordium-5 (P5), pharyngeal stage-primordium25 (P25) and hatching stage $(\mathrm{H})$ ) treated with different concentrations of NP $(0 \mu \mathrm{mol} / \mathrm{L}, 3 \mu \mathrm{mol} / \mathrm{L}, 5 \mu \mathrm{mol} / \mathrm{L}$ and $7 \mu \mathrm{mol} / \mathrm{L}$ ) were analyzed. The housekeeping gene $\beta$-actin was used as the reference gene, and the GATA1expression level in neuroblast stage under $0 \mu \mathrm{mol} / \mathrm{L} \mathrm{NP}$ stress was used as the baseline for qRT-PCR (1.0).

Three replicates were performed per sample. Expression levels of corresponding genes were calculated using the $2^{-\triangle \triangle C T}$ method [47]. The GATA1 expression levels were measured by one-way analysis of variance, followed by Dunnett's tests for multiple comparisons using SPSS Statistics 20 software. $P<0.05$ was considered statistically significant.

Table 5 Primers for others

\begin{tabular}{lll}
\hline $\begin{array}{l}\text { Primer } \\
\text { name }\end{array}$ & Sequence $\left(\mathbf{5}^{\prime} \boldsymbol{\rightarrow} \mathbf{3}^{\prime} \mathbf{)}\right.$ & Application \\
\hline$\beta$-actin -F & GGCCTCCCTGTCTATCTTCC & qRT-PCR \\
$\beta$-actin -R & TTGAGAGGTTGGGTTGGTC & \\
GATA1-F4 & TTATTCGTTGGAGGAG & $\begin{array}{l}\text { methylation sequence } \\
\text { obtaining }\end{array}$ \\
& ATC & \\
GATA1-R4 & CGCTATCTAAAATACTT & \\
& CCACG & \\
\hline
\end{tabular}




\section{Methylation of the GATA1 from C. auratus red var} The genomic DNAs in different developmental stages from the $5 \mu \mathrm{mol} / \mathrm{L}$ NP stress group and control group were extracted, respectively. The DNA was subjected to sulfite modification using the EZ DNA MethylationGold $^{\text {ix }}$ Kit (Zymo Research, China) according to the manufacturer's instructions. The software Methyl Primer Express v1.0 was used to design specific primers GATAF4 / R4 (Table 5) in the 5'UTR region of the GATA1 gene. The PCR products were purified by a Gel Extraction Kit (Omega, USA), and the purification products were ligated into pMD19-T vectors (Takara, Japan). The ligation products were then transformed into competent Escherichia coli DH5 $\alpha$ cells (TransGen, China) and cultured at $37{ }^{\circ} \mathrm{C}$. Positive colonies were selected and sequenced by a Bio-tech company (TIANYI HUIYUAN, China). Fifteen groups of colonies were selected for sequencing at each developmental stage. The sequencing results were sorted and methylation status was analyzed. The degree of methylation was expressed as the percentage of the methylation number of the measured $\mathrm{CpG}$ sites to the total number of the methylation sites measured. Correlation analysis was performed on the expression of GATA1 mRNA and the degree of methylation in the 5'UTR region of GATA1 gene using SPSS Statistics 20 software. The correlation between the two variables was showed by the correlation coefficient (r).

\section{Abbreviations}

NP: Nonylphenol; qRT-PCR: Realtime fluorescence quantitative PCR; G: Gills; L: Liver; S: Spleen; T: Testis; P: Pituitarium; I: Intestines; MK: Middle kidney; M: Muscle; HK: Head kidney; H: Heart; B: Brain; O: Ovary; N: Neuroblast stage; S5: 5 somite stage; S14: 14 somite stage; S21: 21 somite stage; P5: Pharyngeal stage-primordium-5; P25: Pharyngeal stage-primordium-25; H: Hatching stage; STS: Sequence Manipulation Suite; SMART: Simple Modular Architecture Research Tool; NJ: Neighbor-joining; gDNA: Genomic DNA

\section{Supplementary Information}

The online version contains supplementary material available at https://doi. org/10.1186/s12863-021-00966-3.

Additional file $\mathbf{1}$ Checklist S1. Completed "The ARRIVE Guidelines

Checklist" for reporting animal data in this manuscript.

\section{Acknowledgements}

We thank the laboratory members for their technical assistance and constructive comments. Work in our laboratories is supported by the Hunan University of Science and Technology, State Key Laboratory of Developmental Biology of Freshwater Fish and Pearl River Fisheries Research Institute.

\section{Authors' contributions}

YDS, DGZ and MO: initial conceptual and experimental design of the study. YST, XJC and WAC: performed the experiment, interpretation of data, key discussions on principle findings. YST and MO: wrote and edited the manuscript. All authors read and approved the final version of the manuscript.

\section{Funding}

This work was supported by the Scientific Research Project of National Natural Science Foundation of China (31873038), Hunan Provincial science and technology Department (2019NK4218, 2019JJ70038), Hunan Education Department (17A072) and State Key Laboratory of Developmental Biology of Freshwater Fish (2018KF008). Funding bodies played no role in the design of the study or analysis or interpretation of data or in writing the manuscript.

\section{Availability of data and materials}

Data and materials are available from the authors on reasonable request. The GATA1 cDNA sequence is available in the GenBank (Accession number MT322308)

\section{Declarations}

Ethics approval and consent to participate

This study was approved by the Animal Ethical Review Committee (AERC) of Hunan Normal University and followed the guidelines statement of the Administration of Affairs Concerning Animal Experimentation of China. This manuscript does not involve the use of any human data or tissue. The animals used in the study came from Hunan Normal University, and we have obtained written consent from Hunan Normal University to use these animals in our research.

\section{Consent for publication}

Not applicable.

\section{Competing interests}

The authors declare that they have no competing interests.

\section{Author details}

${ }^{1}$ Hunan Key Laboratory of Economic Crops Genetic Improvement and Integrated Utilization, School of Life Sciences, Hunan University of Science and Technology, Xiangtan 411201, Hunan, People's Republic of China. ${ }^{2}$ Key Laboratory of Tropical and Subtropical Fishery Resources Application and Cultivation, Ministry of Agriculture, Pearl River Fisheries Research Institute, Chinese Academy of Fishery Sciences, Guangzhou 510380, Guangdong, Hunan, People's Republic of China.

Received: 22 May 2020 Accepted: 2 March 2021

Published online: 18 March 2021

References

1. $Y u$ J, Wu J, Zhang B, Xu J. Toxic effects of nonylphenol on the organisms and its mechanism. J Environ Hygiene. 2013;3:268-72.

2. Lukac N, Lukacova J, Pinto B, Knazicka Z, Trrda E, Massanyi P. The effect of nonylphenol on the motility and viability of bovine spermatozoa in vitro. Environ Sci. 2013;48(8):973-9.

3. Laws SC, Carey SA, Ferrell JM, Bodman GJ, Cooper RL. Estrogenic activity of octylphenol, nonylphenol, bisphenol a and methoxychlor in rats. Toxicol Sci. 2000;54(1):154-67.

4. Tanaka JN, Grizzle JM. Effects of nonylphenol on the gonadal differentiation of the hermaphroditic fish, Rivulus marmoratus. Aquat Toxicol. 2002;57(3): 117-25

5. Kawana R, Strüssmann CA, Hashimoto S. Effect of p-Nonylphenol on sperm motility in Japanese medaka (Oryzias latipes). Fish Physiol Biochem. 2003; 28(1):213-4

6. Lahnsteiner F, Berger B, Grubinger F, Weismann T. The effect of 4nonylphenol on semen quality, viability of gametes, fertilization success, and embryo and larvae survival in rainbow trout (Oncorhynchus mykiss). Aquat Toxicol. 2005;71(4):297-306.

7. Xiao Q, Xu YY. On the effects of nonylphenol on the embryonic development of Puntius conchonius. J Saf Environ. 2010;10(6):9-12.

8. Zhang QY, Sun YD, Wang ZJ, Hu XJ, Kui X. Toxic effects of Nonylphenol on the embryonic development of goldfish (Carassius auratus). Progress Modern Biomed. 2016;16:3040-3.

9. Willey JB, Krone PH. Effects of endosulfan and nonylphenol on the primordial germ cell population in pre-larval zebrafish embryos. Aquat Toxicol. 2001;54(1-2):113-23.

10. Lü B, Zhan P. Effects of nonylphenol on brain gene expression profiles in F1 generation rats. Toxicol Environ Chem. 2009;91(3):559-65.

11. Nair PMG, Choi J. Modulation in the mRNA expression of ecdysone receptor gene in aquatic midge, Chironomus riparius upon exposure to nonylphenol and silver nanoparticles. Environ Toxicol Pharmacol. 2012;33(1):98-106. 
12. Klempt M, Vobach M, Wiegand H, Preuss TG, Schäffer AKU. 353nonylphenol induces expression of the t-box 6 gene in zebrafish embryos-linking transcriptional information with deformities. J Fish Sci. 2013;7(1):30-42

13. Robertson LS, McCormick SD. The effect of nonylphenol on gene expression in Atlantic salmon smolts. Aquat Toxicol. 2012;122-123:36-43.

14. Meucci $V$, Arukwe A. The xenoestrogen 4-nonylphenol modulates hepatic gene expression of pregnane $X$ receptor, aryl hydrocarbon receptor, CYP3A and CYP1A1 in juvenile Atlantic salmon (Salmo salar). Comparative Biochem Physiol Part C. 2006;142(1-2):142-50.

15. Cocci P, Mosconi G. Palermo F a: effects of 4-nonylphenol on hepatic gene expression of peroxisome proliferator-activated receptors and cytochrome P450 isoforms (CYP1A1 and CYP3A4) in juvenile sole (Solea solea). Chemosphere. 2013;93(6):1176-81.

16. Chan JL, Hu XX, Wang CC. Xu QH: miRNA-152 targets GATA1 to regulate erythropoiesis in Chionodraco hamatus. Biochem Biophys Res Commun. 2018;501(3):711-7.

17. Bárbara FZ, Pavón L, Calés C. CDC6 expression is regulated by lineagespecific transcription factor GATA1. Cell Cycle. 2012;11(16):3055-66.

18. Ling T, Crispino JD, Zingariello M, Martelli F, Migliaccio AR. GATA1 insufficiencies in primary myelofibrosis and other hematopoietic disorders: consequences for therapy. Expert Rev Hematol. 2018;11(3):169-84.

19. Galloway JL, Wingert RA, Thisse C, Thisse B, Zon LI. Loss of Gata1 but not Gata2 converts erythropoiesis to Myelopoiesis in Zebrafish embryos. Dev Cell. 2005;8(1):109-16.

20. Zetterberg E, Verrucci M, Martelli F, Zingariello M, Sancillo L, D'Amore E, Rana RA, Migliaccio AR. Abnormal P-selectin localization during megakaryocyte development determines thrombosis in the gata 1 low model of myelofibrosis. Platelets. 2014;25(7):539-47.

21. Wu DS. Current situation and Prospect of the standardization research and application of laboratory red Crucian carp. Lab Anim Sci. 2016; 33(3):56-60.

22. Lü XH, Gu Y, Song Y. Toxicity and tissue accumulation of nonylphenol in Carassius auratus red variety, Grass Carp and Sliver Carp. J Hygiene Res. 2012; 41(5):785-9.

23. Tian YS, Sun YD, Ou M, Liu YF, Cui XJ, Zhou DG, Che WA. Preliminary studies on the mechanism of nonylphenol-induced malformation of Carassius auratus red var. J Fish China. 2020;44(10):1619-36.

24. Lowry JA, Atchley WR. Molecular evolution of the GATA family of transcription factors: conservation within the DNA-binding domain. J Mol Evol. 2000;50(2):103-15

25. Ito E, Toki T, Ishihara H, Ohtani H, Gu L, Yokoyama M, Engel JD, Yamamoto M. Erythroid transcription factor GATA-1 is abundantly transcribed in mouse testis. Nature. 1993;362(6419):466-8.

26. Yomogida $K$, Ohtani $H$, Harigae $H$, Ito E, Nishimune $Y$, Engel JD, Yamamoto M. Developmental stage- and spermatogenic cycle-specific expression of transcription factor GATA-1 in mouse Sertoli cells. Development. 1994;120(7): 1759-66.

27. Thomas RL, Crawford NM, Grafer CM, Zheng W, Halvorson LM. GATA augments GNRH-mediated increases in Adcyap 1 gene expression in pituitary gonadotrope cells. J Mol Endocrinol. 2013;51(3):313-24.

28. Miyeon C, Wang SE, Ko SY, Kang HJ, Chae SY, Lee SH, Kim YS, Duman RS, Hyeon S. Overexpression of human GATA-1 and GATA-2 interferes with spine formation and produces depressive behavior in rats. PLoS One. 2014; 9(10):e109253.

29. Ye K. Preliminary studies on expression patterns and functional analysis of GATA factors in Nile tilapia. Chongqing: Southwest University; 2012

30. Kwan W, North TE. Netting novel regulators of hematopoiesis and hematologic malignancies in Zebrafish. Curr Top Dev Biol. 2017;124:125-60.

31. Zhang YJ, Mao BY. Developmental expression of an Amphioxus (Branchiostoma belcheri) gene encoding a GATA transcription factor. Zool Res. 2009;30(2):137-43.

32. Martyn U, Merker SS. The ventralized ogon mutant phenotype is caused by a mutation in the zebrafish homologue of sizzled, a secreted frizzled-related protein. Dev Biol. 2003;260(1):58-67.

33. Bauer H, Lele Z, Rauch GJ, Geisler R, Hammerschmidt M. The type I serine/ threonine kinase receptor Alk8/lost-a-fin is required for Bmp2b/7 signal transduction during dorsoventral patterning of the zebrafish embryo. Development. 2001;128(6):849-58.

34. Kim JH, Park JB, Lee JY, Kim J. PV.1 suppresses the expression of FoxD5b during neural induction in Xenopus embryos. Mol Cell. 2014;37(3):220-5.
35. Shibata K, Ishimura A, Maéno M. GATA-1 inhibits the formation of notochord and neural tissue inXenopusEmbryo. Biochem Biophys Res Commun. 1998; 252(1):241-8.

36. Sun ZX, Kang K, Cai YJ, Zhang JQ, Zhai YF, Zeng RS, Zhang WQ. Transcriptional regulation of the vitellogenin gene through a fecundity-related single nucleotide polymorphism within a GATA-1 binding motif in the brown planthopper, Nilaparvata lugens. Insect Mol Biol. 2018;27(3):365-72.

37. Lee KW, Hwang DS, Rhee JS, Ki JS, Park HG, Ryu JC, Raisuddin S, Lee JS. Molecular cloning, phylogenetic analysis and developmental expression of a vitellogenin $(\mathrm{Vg})$ gene from the intertidal copepod Tigriopus japonicus. Comp Biochem Physiol B: Biochem Mol Biol. 2008;150(4):395-402.

38. Tomomasa Y, Satoru T, Naomi M, Takashi K, Masatsugu E, Asami W, Ritsuko $\mathrm{S}$, Osamu O, Motomih O, Hitoshi O. Characterization of GATA-1 ${ }^{+}$ hemangioblastic cells in the mouse embryo. EMBO J. 2007;26(1):184-96.

39. Fujiwara Y, Chang AN, Williams AM, Orkin SH. Functional overlap of GATA-1 and GATA-2 in primitive hematopoietic development. Blood. 2003;103(2): 583-5.

40. Salvaing J, Peynot N, Bedhane MN, Veniel S, Pellier E, Boulesteix C, Beaujean N, Daniel N, Duranthon V. Assessment of 'one-step 'versus' sequential' embryo culture conditions through embryonic genome methylation and hydroxymethylation changes. Hum Reprod. 2016;31(11):2471-83.

41. Stefano LD, Ji JY, Moon NS, Herr A, Dyson N. Mutation of Drosophila Lsdi disrupts H3-K4 methylation, resulting in tissue-specific defects during development. Curr Biol. 2007;17(9):808-12.

42. Samira IR, Mohamed AK, Rita K, Thierry B, Guérin JF, Annick L. Analysis of H19 methylation in control and abnormal human embryos, sperm and oocytes. Eur J Hum Genet. 2011;19(11):1138-43.

43. Feng $Y$, Zhao LZ, Hong L, Shan C, Shi W, Cai W. Alteration in methylation pattern of GATA-4 promoter region in vitamin A-deficient offspring's heart. J Nutr Biochem. 2013;24(7):1373-80.

44. Okada Y, Sakaue H, Nagare T, Kasuga M. Diet-induced up-regulation of gene expression in adipocytes without changes in DNA methylation. Kobe J Med Sci. 2009:54(5):241-9.

45. Milenkovic D, Berghe WV, Boby C, Leroux C, Declerck K, Szic KS, Heyninck K, Laukens K, Bizet M, Defrance M, et al. Dietary Flavanols modulate the transcription of genes associated with cardiovascular pathology without changes in their DNA methylation state. PLoS One. 2014;9(4):e95527.

46. Wang JS, Wei YH, Li XM, Cao H, Xu MQ, Dai JY. The identification of heat shock protein genes in goldfish (Carassius auratus) and their expression in a complex environment in Gaobeidian Lake, Beijing, China. Comparative Biochem Physiol Part C. 2007;145(3):350-62.

47. Livak KJ, Schmittgen TD. Analysis of relative gene expression data using realtime quantitative PCR and the $2^{-\Delta \Delta C T}$ method. Methods. 2001;25(4):402-8.

\section{Publisher's Note}

Springer Nature remains neutral with regard to jurisdictional claims in published maps and institutional affiliations.

Ready to submit your research? Choose BMC and benefit from:

- fast, convenient online submission

- thorough peer review by experienced researchers in your field

- rapid publication on acceptance

- support for research data, including large and complex data types

- gold Open Access which fosters wider collaboration and increased citations

- maximum visibility for your research: over $100 \mathrm{M}$ website views per year

At $\mathrm{BMC}$, research is always in progress.

Learn more biomedcentral.com/submissions 